Proceeding Series of the Brazilian Society of Computational and Applied Mathematics

\title{
Problema de dimensionamento de lotes em uma indústria de móveis seriados
}

\author{
Walter Ribeiro da Rocha Junior ${ }^{1}$
}

Instituto Senai de Tecnologia e Inovação em Madeira e Mobiliário \ Pós Graduação em Engenharia de Produção. Faculdade de Engenharia, UNESP, Bauru, SP

\section{Adriana Cristina Cherri ${ }^{2}$}

Departamento de Matemática - UNESP, Bauru, SP

\section{Silvio Alexandre de Araujo}

Departamento de Matemática Aplicada - DMAP - UNESP, São José do rio Preto, SP

\begin{abstract}
Resumo. Neste trabalho propomos um modelo matemático para resolver o problema de dimensionamento de lotes de produção em uma indústria de móveis. O problema proposto se caracteriza como multi-itens, multi-estágios com demanda dinâmica determinística.
\end{abstract}

Palavras-chave. Dimensionamento de lotes, Indústria moveleira, Modelagem Matemática

\section{Introdução}

Os sistemas de manufatura são constantemente pressionados por melhores resultados. Uma das formas de contribuir com esta condição é aprimorar forma de definição dos lotes de produção. Na literatura este assunto é referenciado como PDL (Problema de Dimensionamento de Lotes) [3]. O PDL faz parte de uma classe de problemas que envolvem decisões de planejamento da produção industrial. Consiste em definir uma estratégia para a utilização da capacidade fabril. As decisões envolvem quais produtos serão produzidos, em quais quantidades e em qual período, de forma a atender a demanda de dentro da melhor relação custo-benefício. Considerando apenas um produto, [1] propõe o modelo Economic Order Quantity (EOQ), sem restrição de capacidade, com demanda estacionária, horizonte infinito e períodos de tempos contínuos. [2] considera o algoritmo de colônia de abelhas para solução o PDL em um sistema de produção multiestágio. Segundo [4], estudos que analisem modelos em planejamento da produção com

${ }^{1}$ walter.ribeiro82@gmail.com

2 adriana@fc.unesp.br

3 saraujo@ibilce.unesp.br 
dados reais envolvem a menor parte dos artigos publicados.

\section{Descrição do Problema}

O problema envolve a dinâmica de planejamento produção em uma indústria de móveis seriados da região de Arapongas, PR. O horizonte engloba período de cinco dias úteis, sendo que a informação é gerada com dois períodos de antecedência e o prazo firmando com o cliente em trinta dias corridos. Uma vez aprovados os pedidos, estes são agrupados em função da localização geográfica do cliente, definindo assim o prazo de entrega. Em paralelo, um levantamento da disponibilidade em estoque por item demandado é realizado. Com base nas necessidades, são definidos quais produtos e em quais quantidades devem ser fabricados.

\section{Conclusão}

Para resolução do problema, foi proposto um modelo matemático linear inteiro misto (MIP), baseado em trabalhos da literatura e nas informações fornecidas pela empresa. O modelo foi implementado em AMPL com o solver CPLEX. Testes iniciais baseados em dados reais comtemplam um horizonte de cinco dias, considerando três modelos de produtos e uma linha de produção composta de sete equipamentos. Os resultados são promissores e serão apresentados no evento.

\section{Agradecimentos}

Os autores agradecem o apoio da FAPESP (Processo no. 2014/01203-5), CNPq (Processo $n^{\circ}$ 477481/2013-2) e SENAI Paraná.

\section{Referências}

[1] F. W. Harris, How many parts to take at once. Factory, The Magazine of Management, vol. 10, 135-136, (1913).

[2] M. M. Furlan, M. Santos, Algoritmo de Colônia de Abelhas Aplicado ao Problema de Dimensionamento de Lotes Multiestágio com Limitação de Capacidade, I CMAC Sudeste, (2011).

[3] S. A. Araújo, S. Rangel, Matemática Aplicada ao Planejamento da Produção e Logística, Notas em Matemática Aplicada, SBMAC, vol. 76, (2014).

[4] M. D. Madroñero, J. Mula, Peidro, D., A review of discrete-time optimization models for tactical production planning, vol. 52, 5171-5205, (2014). 